\title{
Xây dựng chương trình đào tạo bất động sản: Một khảo cứu từ kinh nghiệm của một số quốc gia
}

\section{Real Estate Curriculum: Experiences from other countries}

\author{
Nguyễn Đức Trung ${ }^{1 *}$, Bùi Ngọc Tuấn Anh ${ }^{1}$, Phạm Minh ${ }^{1}$ \\ ${ }^{1}$ Trường Đại học Mở Thành phố Hồ Chí Minh, Việt Nam \\ *Tác giả liên hệ, Email: trung.nd@ou.edu.vn
}

\begin{tabular}{|c|c|}
\hline THÔNG TIN & TÓM TÁT \\
\hline $\begin{array}{l}\text { DOI:10.46223/HCMCOUJS. } \\
\text { proc.vi.16.1.1860.2021 }\end{array}$ & $\begin{array}{l}\text { Thị trường bất động sản Việt Nam luôn có tiềm năng to lớn, } \\
\text { tuy nhiên đi cùng viến cảnh tốt đẹp chúng ta phải thừa nhận } \\
\text { rằng qua nhiều năm phát triển nhưng ngành này vấn chưa tạo ra } \\
\text { nhiều sản phẩm và dịch vụ để tối đa hóa lợi ích khách hàng và } \\
\text { phần lớn vẫn định hướng giao dịch. Hiện tại, đào tạo nguồn } \\
\text { nhân lự ngành bất đông sản đã được môt số trường tai Viêt }\end{array}$ \\
\hline Ngày nhận: 7/3/2021 & Nam áp dụng từ năm 2015 . Trên thế giới, ngày càng nhiều nhà \\
\hline Ngày nhận lại: 30/3/2021 & giáo dục trong lãnh vực này tin rằng giáo dục bất động sản nên \\
\hline Duyệt đăng: 9/4/2021 & $\begin{array}{l}\text { được dạy như một quá trình tương tác chủ động hơn là tự học } \\
\text { qua kinh nghiệm của một số tổ chức và cá nhân chỉ dựa trên } \\
\text { chức năng, con số và sự kiện. Từ thực tế đó, bài viết muốn phân } \\
\text { tích thông tin về chương trình đào tạo ngành bất động sản, ở } \\
\text { một số quốc gia phát triến cho chuyên ngành bậc đại học và } \\
\text { cuối cùng là một số ý kiến dưới gốc độ bối cảnh Việt Nam. }\end{array}$ \\
\hline
\end{tabular}

giáo dục bất động sản, ngành bất động sản, môi trường xây dựng

Keywords:

real estate education, real estate sector, construction environment

\section{ABSTRACT}

Vietnam's real estate market always has dramatic potential. Apart from a bright prospect, it has been admitted that this industry has not yet created as many products and services as it could be to maximize customer benefits and has still oriented largely transactions throught many years of its development. Currently, human resource training in real estate has been introduced by certain schools in Vietnam since 2015. Over the world, educators in this field increasingly believe that real estate education should be taught as formal programs rather than selflearning processes through organizations and individuals' experiences based on separate functions, numbers, and facts. In a response to this situation, our paper aim at analyzing information about real estate undergraduate programs in some developed countries and finally at bringing about some opinions under the context of Vietnam.

\section{Giới thiệu}

Trong khu vực Đông Nam Á, Việt Nam đã và đang được quan tâm với vai trò là một thị trường bất động sản phát triển nhanh và mạnh trong nhiều năm qua. Trong bối cảnh đó, thị 
trường này được coi là điểm nóng của các loại hình bất động sản và trong những năm gần đây thì bất động sản hạng sang đang dần chiếm tỉ trọng lớn hơn. Trong tổng kết của Savills Việt Nam cho thấy thị trường đã phát triển qua 04 giai đoạn từ năm 1995 đến nay và vẫn có nhiều tiềm năng. Sự phát triển này được hỗ trợ bởi nền kinh tế đang phát triển, cùng với luật pháp đã giúp người nước ngoài mua bất động sản dễ dàng hơn. Năm 2018, nền kinh tế Việt Nam tăng trưởng mạnh mẽ 7,1\%, sau khi tăng 6,8\% năm 2017 và 6,2\% năm 2016. Việt Nam được kỳ vọng sẽ tiếp tục tăng trưởng vượt bậc trong những năm tới.

Bên cạnh đó, giáo dục luôn được xem là chìa khóa giúp trang bị cho nguồn nhân lực trong ngành kiến thức và kỹ năng cần thiết trở nên hữu ích và đóng góp vào sự phát triển của quốc gia, mang lại năng suất cao hơn cho đất nước. Trong những năm gần đây, giáo dục bất động sản ngày càng được chú ý nhiều hơn. Trong bối cảnh Việt Nam với hầu hết khi hình dung về bất động sản chỉ hình dung đến hầu hết các hoạt động định hướng mua bán hoặc đầu tư. Tuy nhiên, thực tế phát triển của các nước trên thế giới cho thấy lãnh vực bất động sản có thể cung cấp nhiều sản phẩm đa dạng hơn như quản lý sơ sở hạ tầng, quản lý tài sản, quản lý vị trí và nhiều dịch vụ cũng như thông tin đi kèm. Trong tài liệu Successful Corporate Real Estate Strategies (tạm dịch: Các chiến lược thành công cho công ty bất động sản) đã định nghĩa về lãnh vực quản trị công ty bất động sản thông qua quản lý danh mục đầu tư bất động sản của tập đoàn bằng cách điều chỉnh danh mục đầu tư và dịch vụ phù hợp với nhu cầu của hoạt động kinh doanh cốt lõi (quy trình), để đạt được giá trị gia tăng tối đa cho doanh nghiệp và đóng góp tối ưu vào hiệu quả hoạt động chung của tập đoàn (Dewulf, Krumm, \& Jonge, 2000).

Mục tiêu của tham luận này là tìm hiểu hiện trạng và quan điểm của giáo dục ngành bất động sản và các nghiên cứu cơ bản trên thế giới. Bài viết được xoay quanh việc giải quyết câu hỏi: Những kiến thức chuyên môn nào cần cho học viên chuyên ngành bất động sản để có khả năng đáp ứng thị trường bất động sản ở Việt Nam.

Bài tham luận sẽ trình bài ví dụ điển hình đào tạo chuyên ngành bất động sản ở một số nước phát triển trước khi đi sâu vào nghiên cứu nhu cầu nội dung đào tạo ở một số quốc gia và cái nhìn ứng dụng vào bối cảnh Việt Nam.

\section{Nhu cầu xã hội cho giáo dục và đào tạo bất động sản}

Nước Pháp là một trong số nước phát triển có chương trình đào tạo bậc đại học chuyên ngành bất động sản từ khá sớm. Các chương trình đào tạo mới ở nước này, tập trung hơn vào quản lý bất động sản và tài chính, đã được phát triển nhanh chóng. Kể từ giữa thập niên 1990, các văn bằng mới đã và các chương trình đào tạo mới được đưa ra. Theo nguyên tắc chung, chương trình đào tạo này được phân biệt theo thời gian đào tạo ban đầu ngắn hoặc dài (Cấp độ thứ nhất hoặc thứ ba của đại học) do các trường đại học công lập, các trường tư thục hoặc các trường đại học tư thục cung cấp, hoặc cách khác là đào tạo nghề hoặc giáo dục thường xuyên.

Hệ thống giáo dục của Pháp là duy nhất trong việc cung cấp cho sinh viên ba chương trình giáo dục khác nhau và bổ sung sau Tú tài - Baccalaureate (cấp độ $\mathrm{A}$ ): các khóa học cấp bằng đại học; các chương trình học nâng cao trong các trường đại học (trường quản lý hoặc kỹ thuật); và các chương trình chuyên biệt như nghệ thuật, kiến trúc hoặc thiết kế. Hiện tại, giáo dục bất động sản cấp cao nhất được cung cấp bởi cả trường đại học và trường quản lý (grandes ecoles).

Nội dung giảng dạy ở bậc đại học được tổ chức thành ba cấp độ. Hiện tại, chỉ có cấp độ thứ ba của các khóa học đại học Pháp cung cấp chương trình đào tạo bất động sản, dưới hình thức DESS (Diploma Ome d'Etudes Superieures Specialisees - Diploma in Higher Professional Studies). Các khóa học DESS theo định hướng chuyên nghiệp này thu nhận sinh viên sau khi có 
bằng tốt nghiệp cấp độ 2 , chẳng hạn như bằng Thạc sĩ hoặc bằng tốt nghiệp Grande Ecole. Số lượng DESS trong lĩnh vực bất động sản đã tăng lên đáng kể trong một những năm đầu của thập niên 2010. Tuy nhiên, phần lớn các chương trình của cấp độ 3 này vẫn thường xuyên quan tâm đến việc đào tạo dành riêng cho luật bất động sản và xây dựng. Ở Pháp, hiện có khoảng 20 văn bằng đại học thứ ba chủ yếu là ngành luật.

Mặt khác, sự mở cửa của DESS trong lĩnh vực tài chính bất động sản hoặc kinh tế vẫn còn ít phát triển và phản ánh sự phát triển quá mức gần đây của các ngành nghề mới trong tài chính bất động sản và quản lý tài sản ở Pháp. Ví dụ về các khóa học có sẵn là: DESS về Quản lý Bất động sản tại ESSEC và Đại học Poitiers; DESS về Quản lý Bất động sản và Bất động sản tại Đại học Toulon; DESS về Kỹ thuật Bất động sản tại Đại học Marne-la-Vallee; và DESS về Kỹ thuật Bất động sản tại Đại học Paris XII.

Kể từ đầu thế kỷ 21, một số trường đại học và trường học ở Hoa Kỳ và Châu Âu cung cấp cho học viên đại học và sau đại học khả năng tham gia vào các chương trình bất động sản ngắn hơn và dài hơn ở những mức độ khác nhau. Câu hỏi đặt ra là liệu các chương trình này ở nước ngoài có hữu ích hay không và liệu chúng có giá trị gia tăng hay không. Các câu hỏi bổ sung bao gồm:

(1) Giảng viên và sinh viên xem giá trị gia tăng thực sự của các chương trình là gì?

(2) Các chương trình này là tự chọn hay bắt buộc?

(3) Các phương pháp đánh giá đang được sử dụng có phù hợp để chứng minh tín chỉ học tập mà sinh viên có thể đạt được không?

(4) Các công cụ khảo sát đánh giá có đủ để cải thiện các chương trình không?

(5) Các chương trình ở nước ngoài có phải là một hình thức giáo dục bất động sản hiệu quả không?

(6) Điều gì có thể được cải thiện?

Nhìn lại lịch sử của sự phát triển đào tạo bất động sản, Palm và Pauli (2018) đã chỉ ra nhu cầu nhân sự có bằng tốt nghiệp đại học đã thúc đẩy sự gia tăng nhanh các chương trình đào tạo bất động sản ở các bậc khác nhau trên toàn thế giới. Thực tế cho thấy, các chương trình đại học chuyên ngành về bất động sản đã phát triển về số lượng để đáp ứng nhu cầu ngày càng tăng đối với những người muốn có kiến thức chuyên ngành và chuyên môn để phát triển sự nghiệp. Một trong những mục tiêu quan trọng của một chương trình đại học là để trang bị cho sinh viên tốt nghiệp kiến thức và kỹ năng cập nhật theo yêu cầu của ngành đó. Nếu không, rõ ràng, sẽ không có bất kỳ nhu cầu nào về sinh viên tốt nghiệp chuyên ngành bất động sản, và điều này cũng đúng với bất kỳ chương trình đại học nào. Trong thời đại ngày nay, môi trường việc làm ngày càng cạnh tranh, sinh viên tốt nghiệp được mong đợi chứng minh rằng họ có những kỹ năng cần thiết được nhà tuyển dụng đánh giá cao (Washer, 2007). Do đó, các khoa hoặc các trường quản lý chương trình sẽ thiết kế các nội dung học phần đáp ứng những thách thức mà sinh viên tốt nghiệp có thể gặp phải khi họ bước vào thị trường lao động.

\section{Bối cảnh ngành bất động sản}

\subsection{Mô hình không gian xã hội}

Các câu hỏi về vai trò của ngành tài sản/bất động sản trong xã hội có thể lý giải dựa trên bộ câu hỏi $5 \mathrm{~W} 1 \mathrm{H}$ gồm cách nào, ở đâu, khi nào, loại nào, cái gì và tại sao để xác định nhu cầu về hàng hóa và dịch vụ tài sản. Các mô hình không gian xã hội cuối cùng được thể hiện trong các quyết định ảnh hưởng đến các vùng kinh tế, loại tài sản, hình thức đầu tư, chiến lược kinh doanh, 
cung cấp dịch vụ, nhu cầu dịch vụ công và kết quả tài khóa của chính phủ. Một số câu hỏi toàn cầu ở cấp độ lớn hơn, có ý nghĩa chính đối với lĩnh vực bất động sản, bao gồm:

- Nhu cầu sẽ ở đâu?

- Làm thế nào để một doanh nghiệp định hướng địa phương phục vụ một thị trường toàn cầu?

- Địa điểm nào co bộ phận văn phòng và bán hàng?

- Những tác động của nền kinh tế thông tin đối với nhu cầu tài sản?

- Các hình thức quản trị sẽ phát triển như thế nào?

- Cơ hội và tác động của các hình thức tài sản mới là gì quyền sở hữu?

- Lý thuyết nào về quy hoạch phát triển thành thị và nông thôn sẽ chiếm ưu thế?

Câu trả lời cho bảy câu hỏi này phản ánh các chủ đề mới của các mô hình không gian xã hội (Roulac, 1998). Nói chung, câu trả lời cho những câu hỏi này là các mô hình không gian xã hội. Khi các mô hình không gian xã hội nhất quán và không đổi, thì các hoạt động tài trợ tài chính là tương đối nhất quán và không đổi. Khi các mô hình không gian xã hội thay đổi, các phương thức tài chính cũng thay đổi theo. Trong số các chủ đề xác định lại các mô hình không gian xã hội là:

- Các hình thức tổ chức mới;

- Công nghệ mới để thực hiện công việc và thương mại;

- Các giá trị mới, nhấn mạnh đến sự cân bằng tâm linh, cộng đồng và lối sống;

- Nhân khẩu học bao gồm dân số lớn tuổi, trẻ em đang trưởng thành bùng nổ, tiếp tục nhập cư, đa dạng văn hóa và đa dạng hơn về lối sống.

Những chủ đề này có ý nghĩa chính yếu đối với các hoạt động đầu tư tài sản và tài chính. Các mô hình không gian xã hội cuối cùng được thể hiện trong các quyết định ảnh hưởng đến các vùng kinh tế, loại tài sản và hình thức đầu tư. Hoạt động kinh tế ngày càng bị ảnh hưởng nhiều hơn bởi các giá trị xã hội, khái niệm và thiết kế sản phẩm, công nghệ, nhà cung cấp, nhà sản xuất và người bán hàng ở những nơi xa nơi tiêu thụ hàng hóa và dịch vụ. Tỷ lệ hàng hóa và dịch vụ do các thương gia địa phương cung cấp được thu hẹp lại do các công ty địa phương sản xuất và phân phối.

Những tiến bộ của thông tin và viễn thông làm tăng đáng kể tính kinh tế, tính di động, sức mạnh và khả năng tiếp cận thông tin. Bên cạnh đó, tiến bộ công nghệ khác đồng thời giới thiệu các mô hình tổ chức rất đa dạng, dẫn đến các hình thức làm việc, mua sắm, sống và giải trí khác nhau. Đã có sự dịch chuyển các giao dịch kinh doanh diễn ra vào thời gian, địa điểm và sự thuận tiện của người bán sang thời gian, địa điểm và sự thuận tiện của người tiêu dùng. Vào thời điểm mà những tiến bộ trong viễn thông làm cho khoảng cách không thích hợp trở thành một hạn chế, việc đi lại nói chung, và đặc biệt là quốc tế, đang tăng mạnh. Những lực lượng này có tác động mạnh mẽ đến nhu cầu tài sản.

Việc tách biệt giao dịch khỏi môi trường thực tế do hỗ trợ của giao dịch trực tuyến cũng như xác định lại vai trò của trụ sở công ty là hệ quả của việc khả năng kết nối làm việc ngoài văn phòng phổ biến. Trong đợt dịch Covid 19 từ đầu năm, rất nhiều công ty và tổ chức ở Việt Nam dù chủ động hay bị động đều đa phần đã áp dụng hình thức làm việc tại nhà và trải nghiệm này lần nữa cho chúng ta thấy sự giảm thiểu việc phải có văn phòng cố định. Một chương trình nghị sự rất khác về các yếu tố địa điểm được đưa ra từ những chuyển biến nhu cầu giảm thiểu các 
không gian vật lý. Sự kết hợp của viễn thông điện tử và các hệ thống giao nhận hậu cần tiên tiến làm thay đổi đáng kể các thông số về khoảng cách của người lao động và khách hàng đến địa điểm làm việc.

Mặc dù từng là trung tâm của lĩnh vực chiến lược, như được phản ánh trong đánh giá của Napoléon rằng "chiến lược là nghệ thuật tận dụng thời gian và không gian", trong phần lớn thời gian của thế kỷ 20 , phần lớn địa lý đã được những người chịu trách nhiệm xây dựng chiến lược doanh nghiệp xem xét. Trong nghiên cứu của mình Schulte (2012) chỉ ra các vấn đề dựa trên đất đai là nền tảng của lý thuyết kinh tế sơ khai, dưới dạng công trình quan trọng như của David Ricardo vào năm 1911 liên quan đến địa tô và Thomas Malthus năm 1798 liên quan đến tương tác giữa dân số và năng suất, các vấn đề về địa lý kinh tế không gian cho phần lớn thế kỷ trước đã được chỉ định một mức độ ưu tiên đã giảm đi nhiều. Nhưng ngày nay, đồng thời với sự phục hưng của các ý tưởng lớn trong quản lý chiến lược, các nhà lý thuyết và nhà kinh tế học quản lý chiến lược cũng dành sự quan tâm ngày càng nhiều đến các vấn đề về vị trí và địa lý.

Một mô hình tài sản theo không gian xã hội cụ thể có thể được truy ngược lại thông qua một số quy trình và các một số phương pháp luận của quy luật phù hợp trong ngành để xác định giá trị. Đối với mọi quyết định về tài sản tác động đến giá trị phản ánh việc giải thích các giá trị thông qua các thể chế, quy tắc, thủ tục, các bên tham gia và thị trường bao gồm lĩnh vực bất động sản được định nghĩa rộng rãi. Mọi yếu tố cấu thành của quá trình tài sản đều được thông báo bởi các giá trị cốt lõi và cuối cùng được phản ánh trong các mô hình không gian xã hội. Đầu ra của quá trình bất động sản (property process) được phản ánh trong giá trị của nhiều quyền lợi liên quan đến tài sản.

Sử dụng từ vựng trong chuyên ngành bất động sản, sẽ hữu ích khi nghĩ rằng "các giá trị”" đại diện cho "nền tảng" của cấu trúc trong ngành tài sản và các "mô hình không gian xã hội societal spatial pattern" như đại diện cho căn hộ áp mái trong bất động sản. Một căn hộ áp mái trong một tòa nhà nhiều tầng được đánh giá là thành công thông qua việc áp dụng hiệu quả nhiều nhiệm vụ, liên quan đến nguồn lực đáng kể, thời gian, tiền bạc và vật liệu. Cần thiết như nền móng, không có nghĩa là nền móng đủ để xây dựng một dinh thự có thể hỗ trợ căn hộ áp mái. Nhiều tầng phải được thêm vào nền móng, với mỗi tầng bao gồm nhiều thành phần và đòi hỏi sự phối hợp đồng tâm và áp dụng các kỹ năng cao.

Một quan điểm khác liên quan đến chuyên ngành tài sản là xem xét rằng các "giá trị”" quyết định thế giới quan phổ biến mà chính những cách nhìn nhận thế giới này ảnh hưởng đến các mô hình không gian xã hội mà cuối cùng điều này xác định giá trị tài sản. Sự quá độ và chuyển tiếp từ và giữa các giá trị sang kết quả tài sản được hỗ trợ, thúc đẩy, định hình và hình thành bởi các yếu tố cấu thành tập thể của chuyên ngành tài sản - thể chế, quy tắc, quy định, quy trình, thủ tục, bên tham gia, chức năng, thị trường, lý thuyết, khái niệm và mô hình - và bằng các quyết định và hành động của vô số các sáng kiến về tài sản - bao hàm tư tưởng hàng đầu, kích thích và ràng buộc của chính phủ, sáng kiến kinh doanh, quyết định kinh doanh, lựa chọn hộ gia đình, sở thích của nhà đầu tư, cạnh tranh về nguồn lực và thực hành nghề nghiệp. Kết quả tài sản là sản phẩm phụ của cách các giá trị của xã hội được chuyển thành các mô hình không gian xã hội thông qua vô số các thể chế, quy trình, quy định, thực hành và người chơi và quyết định của họ.

Kiến thức cần thiết để tham gia vào ngành bất động sản hiệu quả trong bối cảnh toàn cầu nhất thiết phải tạo cầu nối cho khả năng giải quyết hiện tại một cách xây dựng và chuẩn bị cho việc bắc cầu từ hiện tại sang tương lai mà có lẽ sẽ phản ánh sự thay đổi sâu sắc. Trọng tâm để tham gia vào tài sản hiệu quả là năng lực nhận biết, thích ứng và dẫn dắt sự thay đổi. Khi xã hội bước sang thế kỷ 21 , ngành bất động sản cũng như tất cả những người làm việc bên trong nó và 
chịu ảnh hưởng của nó, sẽ trải qua những thay đổi nhỏ. Những thay đổi có thể xét đến như:

- Sửa đổi các mô hình sử dụng không gian truyền thống và các chức năng được thực hiện trong các loại bất động sản;

- Đưa ra những ảnh hưởng mới đến các quyết định về địa điểm không gian;

- Xác định lại các thông số về giá trị bất động sản;

- Thay đổi nhu cầu cấu trúc cơ bản, dẫn đến ít hơn, trong tổng thể, ở các địa điểm khác nhau và các loại khác nhau;

- Tác động đến chiến lược, cơ cấu và hệ thống tổ chức phục vụ những người tham gia và sử dụng bất động sản;

- Tạo ra các nhu cầu mới về các dịch vụ chuyên nghiệp;

- Nâng cao một tiêu chuẩn mới về kiến thức, kỹ năng và phong cách cần thiết của các chuyên gia làm việc trong lĩnh vực bất động sản;

- Làm cho nhiều nguyên tắc và phương pháp thực hành được chấp nhận của ngày hôm qua đã lỗi thời.

Bất kỳ chương trình giảng dạy bất động sản nào không chuẩn bị cho các chuyên gia bất động sản về tác động của các lực thay đổi này, theo định nghĩa, theo định nghĩa, sẽ không hoạt động (Roulac, 1996).

\subsection{Sụ̂ thay đổi của chuyên ngành bất động sản}

Ngành bất động sản ngày nay chịu những sức ép lớn lao định hình lại các thuộc tính của nó và đưa ra những kỳ vọng mới cho những người có liên quan đến tài sản nói chung. Trong số những điều cần cân nhắc là:

+ Đô thị hóa: Đô thị hóa là vấn đề thực tế không chỉ ở Việt Nam và những tác động tich cực và tiêu cực của nó đã được nghiên cứu ở nhiều vấn đề xã hội. Trong đó, bất động sản với vai trò của mình chắc chắn là bên liên quan then chốt của quá trình này

+ Tiến bộ công nghệ: Sự phát triển trong viễn thông và công nghệ thông tin làm thay đổi đáng kể phương tiện và địa điểm làm việc, thay đổi những hoạt động diễn ra trong không gian vật lý và điểm điểm của những không gian vật lý đó

+ Quan tâm đến môi trường: Nhiều người chú trọng hơn về tinh thần của không gian sống và tính bền vững của môi trường, việc coi sản phẩm như một loại hàng hóa ngày càng suy giảm. Ngày nay, đa phần khách hàng mong đợi tìm kiếm những giá trị trải nghiệm nhiều hơn trong ngành bất động sản

+ Toàn cầu hóa: Các doanh nghiệp kinh doanh mở rộng phạm vi hoạt động của các mối quan tâm về địa lý, thu hút các nguồn lực từ các thị trường từ xa và bán hàng trên khắp thế giới, sự gần gũi về vật chất không còn là phương châm xác định chính hoặc gây hạn chế tiếp cận lao động và khách hàng

+ Nguồn lực chiến lược: Các công ty ngày càng nhận ra môi trường làm việc và các cơ sở bán lẻ ảnh hưởng đến khả năng đạt được các mục tiêu chiến lược của tổ chức

+ Tương tác Nhà nước-Tư nhân: Bản chất của phát triển đô thị lớn, liên quan đến việc kết nối các mục tiêu chính sách công và động cơ của khu vực tư nhân, đòi hỏi quan hệ đối tác kết hợp các thuộc tính xã hội và tài chính của tài sản. 
Xuất phát từ sáu thay đổi mạnh mẽ này, cần có một khuôn khổ liên kết chặt chẽ để cho phép những bên liên quan hiểu được tổng thể các hiện tượng, áp lực và mối quan hệ liên quan đến ngành bất động sản. Hơn nữa, mỗi người chơi tìm kiếm một khuôn khổ phù hợp với vai trò và mục đích của họ để hợp lý hóa cách họ nhận thức và tương tác với các địa điểm, không gian, tài sản và bất động sản cũng như những người chơi khác.

\section{4. Đào tạo chuyên ngành bất động sản}

\subsection{Quan điểm đào tạo ngành bất động sản}

Hiểu mối quan hệ của các quan điểm khác nhau về Địa điểm-Tài sản-Bất động sản-Cơ sở tiện ích (place-property-real estate-facilities) là điều cần thiết để xác định kiến thức liên quan đến cấp độ nào. Một chương trình giảng dạy nhằm chuẩn bị cho mọi người hiểu biết về những cân nhắc liên quan đến định hướng cơ sở vật chất rất khác so với những gì sẽ liên quan đến định hướng tài sản. Trong một phần tư cuối của thế kỷ 20 , đã nổi lên một sự phân biệt rõ ràng giữa quan điểm của Anh và Mỹ đối với giáo dục liên quan đến tài sản và bất động sản.

Hamzah, Yahya, Sarip, và Adnan (2016) nhận định rằng ngành bất động sản là các ngành nghề bao gồm định giá, tiếp thị, đại lý, tư vấn, phát triển và quản lý bất động sản là những ngành đóng góp đáng kể cho nền kinh tế. Tuy nhiên, nhóm tác giả cũng nhận thừa nhận rằng cho đến nay vẫn chưa được nghiên cứu kỹ lưỡng để đi đến kết luận đồng thuận về phạm vi chính xác cho giáo dục bất động sản.

Trong khi trước đó, phương pháp tiếp cận giáo dục đại học của Mỹ cân nhắc về phạm vi tài sản/bất động và cách thức quả lý, thì trong vài thập kỷ cuối của thế kỷ 20 , trọng tâm này bị thu hẹp lại, dẫn đến các chương trình giảng dạy theo chiều hướng bất động sản và quan điểm hạn chế hơn về ngành học, nội dung chương trình giảng dạy và các sư phạm. Vào cuối thế kỷ 20 , một số lượng đáng kể các học giả bất động sản Hoa Kỳ đặt trọng tâm chính vào tài chính trong cách tiếp cận chủ đề của họ, điều này không phù hợp với việc xem xét rằng phần lớn các học giả bất động sản đều thuộc về hoặc có mối liên quan với trường khoa tài chính (Webb \& Albert, 1995).

Trong khi đó, các phương pháp tiếp cận xây dựng chương trình ở Anh tiếp tục phản ánh tính ưu việt của bất động sản, với một cái nhìn rộng hơn về lĩnh vực này. Liệu sự thống trị của quan điểm tài chính có phải là mô hình phù hợp và ưa thích cho các hoạt động liên quan đến tài sản và bất động sản hay không đã bị thách thức bởi một số nhà lãnh đạo trường phái này như Diaz (1993), Graaskamp (1976) và Roulac (1996). Những người muốn có một sự nghiệp chuyên môn trong lãnh vực tài sản hoặc liên quan đến tài sản phải tự học hỏi trong việc thiết kế chương trình học và đào tạo chuyên môn của họ.

Theo Schulte, Schulte-Daxbo“k, Holzmann, và Wiffler (2005), các mô hình giáo dục bất động sản có thể được phân biệt thành ba cách tiếp cận giáo dục:

(1) Cách tiếp cận đầu tư và tài chính (chiếm ưu thế ở Hoa Kỳ);

(2) Cách tiếp cận khảo sát thực nghiệm (thường thấy ở Vương quốc Anh và một số quốc gia thuộc Khối thịnh vượng chung Anh);

(3) Cách tiếp cận liên ngành (được áp dụng ở nhiều nước Châu Âu).

Schulte (2012) cho rằng nếu một người theo đuổi học tập và nghiên cứu bậc đại học và thậm chí sau đại học ở Hoa Kỳ, thì người đó rất có thể sẽ tham gia các khóa học và chủ yếu học với các giáo sư có chuyên môn trong hoặc liên hệ với khoa tài chính thuôc một trường đại học đa ngành hoặc chuyên ngành kinh doanh. Một chương trình giảng dạy như vậy có thể cung cấp khả năng tiếp xúc toàn diện với nhiều lĩnh vực kinh doanh, mà việc tiếp xúc với tất cả các lĩnh vực 
kinh doanh đều rất phức tạp, vì bản thân mỗi tài sản là một doanh nghiệp. Tuy nhiên, một khóa học ở trường Đại học Kinh doanh như vậy sẽ bỏ qua việc học có thể đạt được thông qua Trường Đại học Môi trường Xây dựng Vương quốc Anh (United Kingdom School of the Built Environment), với trọng tâm là chương trình giảng dạy khảo sát cổ điển, liên quan đến định hướng ngành về cơ bản gần với các vấn đề đất đai hơn.

Do đó, thật kỳ lạ khi có vẻ như phần lớn sinh viên tốt nghiệp chương trình bất động sản Hoa Kỳ có thể không biết gì về chủ đề địa lý, và một số chủ đề liên quan đến các vấn đề bất động sản và địa điểm cụ thể như thế nào. Nếu lựa chọn khóa học tại Vương quốc Anh, sinh viên sẽ tiếp xúc nhiều hơn với thực tế bất động sản, theo truyền thống khảo sát cổ điển. Những sinh viên này học trong ngôi trường có môi trường xây dựng sẽ có kiến thức cụ thể hơn về những thứ hữu hình hơn so với các học viên cùng chuyên ngành ở Hoa Kỳ. Nền tảng này chuẩn bị tốt hơn cho những sinh viên tham gia vào thị trường lao động sau này.

Tuy nhiên, trường phái cổ điển đa phần tập trung vào Môi trường xây dựng cũng có những điểm bất lợi riêng. Hai trong số các bất lợi lớn nhất đó là sinh viên hoàn thành xong trương trình đào tạo này có xu hướng ít tiếp xúc với quản trị kinh doanh và khả năng thu phân tích sự tác động của môi trường kinh doanh. Sự thiếu sót thứ hai chính là thiếu kiến thức, quan điểm và các công cụ phân tích tiên tiến mà sinh viên tốt nghiệp ngành quản trị kinh doanh và luật có được trong những năm tháng ngồi trên ghế giảng đường. Những sinh viên tốt nghiệp ở Anh này có thể gặp bất lợi lớn trong việc cạnh tranh với các đồng nghiệp có kiến thức về quản trị kinh doanh và luật (Schulte, 2012).

Từ so sánh ở trên chúng ta có thể thấy được có sự khác nhau giữa chương trình học của các chương trình đào tạo đại học về kiến thức cần thiết cho lĩnh vực tài sản này đặc biệt có ý nghĩa do thành phần thay đổi của những người có ảnh hưởng lớn nhất đến các quyết định quan trọng liên quan đến thiết kế, tạo và sử dụng môi trường xây dựng. Trong thế kỷ 21 , tài sản/ bất động sản ngày càng bị thống trị bởi những người có nền tản học vấn trong lãnh vực tài chính và công nghệ, những người với rất ít kiến thức về tài sản và bất động sản. Kiến thức cần thiết để tham gia hiệu quả vào quản trị bất động sản trong bối cảnh toàn cầu dựa trên tính ưu việt của nó, như đã mô tả ở trên, là cách tiếp cận ở cấp độ cao hơn và phạm vi rộng hơn so với bất động sản.

Từ những tìm hiểu đó, nhìn chung hiện tại có hai trường phái đào tạo lớn trong ngành bất động sản và mỗi hướng sẽ có những ưu nhược điểm của riêng nó. Tu nhiên, vấn đề nằm ở chỗ việc thiết kế chương trình chưa dựa trên nhu cầu của những bên liên quan quan trong nhất. Tiếp theo, nhóm tác giả khảo cứu một số chuyên môn có thể đóng góp định hướng các kiến thực và năng lực cần thiết cho chuyên ngành bất động sản.

Schulte và cộng sự (2005) cho rằng chương trình này có tính chất đa ngành. Các khóa học bao gồm trong chương trình là quản trị kinh doanh và bất động sản, kinh tế, luật, quy trình xây dựng, phân tích thị trường, tài chính và thẩm định bất động sản, chiến lược, và các khóa học liên ngành về phát triển bất động sản được thảo luận trong bài báo này. Đây chính là hướng mà các quốc gia Châu Âu đang theo đuổi và cũng có thể là nguồn tham khảo tốt cho các chương trình đào tạo ở Việt Nam.

\section{2. Đào tạo ngành bất động sản tại Việt Nam}

Ngành bất động sản đã được đào tạo ở một số trường tại Việt Nam có thể kể đến như Đại học Kinh tế Quốc dân; Đại học Kinh tế Tp.HCM; Đại học Tài chính - Marketing; Đại học Nông Lâm - Đại học Huế; Đại học Duy Tân; và Đại Học Lâm nghiệp. Theo tìm hiểu của nhóm tác giả về chương trình đào tạo được công bố của một số trường, chương trình đào tạo hiện tại tập trung theo hai hướng. Đầu tiên, hướng giáo dục đặt trọng tâm vào đánh giá tài chính với nhiều môn 
như Đầu tư tài chính, Định giá đầu tư, Đầu tư và tài chính bất động sản. Hướng còn lại tập trung vào Kinh doanh bất động sản với một số môn học được đưa vào thêm bên cạnh các khối kiến thức về tài chính như Chiến lược kinh doanh bất động sản, Pháp luật kinh doanh bất động sản, Đàm phán trong kinh doanh bất động sản.

Nhìn chung, hai hướng đào tạo đều có những nét tương đồng như cách của các trường Đại học ở Hoa Kỳ xây dựng chương trình trọng tâm nhiều vào lãnh vực tài chính. Tầm quan trọng của lãnh vực tài chính và đâu tư là không thể phủ nhận nhưng riêng trong chuyên ngành bất động sản chúng ta cần người học có thêm một số kiến thức về chuyên môn sâu về địa lý, văn hóa, và xây dựng để có thể góp phần phát triển bền vững hơn. Ngoài ra, với những kiến thức của các ngành liên quan đến xây dựng sẽ giúp người học tăng được lợi thế cạnh tranh từ khả năng cung cấp thêm những tư vấn thích hợp cho khách hàng đối với những quyết định đầu tư lâu dài hoặc những trải nghiệm dịch vụ trong một số thị phần bất động sản cao cấp, đây là tiềm năng phát triển trong tương lai của thị trường. Một báo cáo đưa ra vào năm 2017 của Knight Frank ước tính số người Việt Nam với tài sản ròng từ 30 triệu USD trở lên đã tăng $320 \%$ trong giai đoạn 2006-2016, tốc độ gia tăng gần như đứng đầu thế giới, vượt qua cả Ấn Độ và Trung Quốc.

\subsection{Kiến thức cần thiết về chuyên ngành bất động sản}

Khả năng đưa ra các quyết định về tài sản sáng suốt có thể được xem một cách ẩn dụ là nguồn thượng nguồn định hướng dòng chảy đến người dùng hạ lưu. Nguồn ngược dòng số ít này là tổng hợp của lý thuyết, lịch sử, nội dung, bối cảnh, quy trình, phương pháp luận. Sự phát triển của chuyên ngành tài sản bao gồm nhiều quan điểm về cấp phép, chỉ định chuyên môn, giáo dục đại học, giáo dục thường xuyên dành cho người lớn, cách áp dụng cho các khóa học, nghiên cứu lý thuyết, nghiên cứu ứng dụng, ứng dụng nhiều mặt của lý thuyết và học tập cũng như nhiều mối quan tâm của cộng đồng. Định hướng hiện đại của ngành này được phản ánh trong các mô hình khác nhau được sử dụng để xem xét tài sản, bao gồm kinh tế, tài chính, địa lý, kỹ thuật, sử dụng cao nhất và tốt nhất, quy hoạch thành phố, môi giới, pháp lý, quyết định của công ty, giao dịch tiêu dùng và đa lĩnh vực tiếp cận.

Tham gia vào quá trình ra quyết định bất động sản một cách hiệu quả sử dụng nhiều quan điểm và bộ kỹ năng để giải quyết các câu hỏi quan trọng để tham gia vào quá trình ra quyết định tài sản một cách hiệu quả và áp dụng khả năng sắp xếp lại các vấn đề, lựa chọn các phương pháp và công cụ phù hợp, thu thập thông tin cần thiết và tự giáo dục (self-educating) để tìm hiểu những gì một người cần biết để giải quyết các vấn đề mà cá nhân đang gặp phải. Đồng thời, nó phản ánh ý thức về lịch sử của chuyên ngành tài sản, bao gồm kiến thức về các tác lực đã định hình các địa điểm, không gian và hình thái đô thị đương đại cũng như các nhà lãnh đạo tư tưởng của ngành, bao gồm Graaskamp, Ratcliff, Wendt và Zeckendorf cùng với một số cá nhân vẫn đang hoạt động đến thập niên đầu của thế kỷ 21 .

Schulte (2012) cung cấp định hướng sáng suốt để hỗ dẫn dắt giáo dục và nghiên cứu về bất động sản, người có chuyên ngành bất động sản cần có nền tảng quản trị kinh doanh được hỗ trợ bởi các nghiên cứu liên ngành và kinh tế, luật, quy hoạch vùng, kiến trúc và kỹ thuật. Hai sản phẩm chính của bất động sản là:

Các tổ chức - nhà phát triển bất động sản, nhà đầu tư bất động sản, công ty xây dựng, tổ chức tài chính, nhà tư vấn, người sử dụng tài sản và những người khác cung cấp các dịch vụ: (1) quản lý danh mục đầu tư chiển lược, quản lý tài sản doanh nghiệp / bất động sản, quản lý tài sản công / bất động sản; (2) chức năng - phân tích tài sản, định giá, đầu tư tài sản, tài chính tài sản, tiếp thị tài sản; và (3) Xác định các giai đoạn cụ thể - phát triển, quản lý dự án, quản lý cơ sở vật chất - các khía cạnh của quản lý (Schulte, 2000). 
Để đạt được hiệu quả trong các hoạt động liên quan đến tài sản, chương trình đào tạo phải đồng thời và cung cấp các quan điểm:

- Nhà sử học

- Nhà nghiên cứu hành vi

- Công dân toàn cầu

- Nhà quy hoạch đô thị

- Nhà địa lý

- Nhà chiến lược kinh doanh

- Người theo chủ nghĩa vị lai

- Nhà kinh tế chính trị

- Chuyên gia thông tin

Những quan điểm này vượt qua phạm vi của phần lớn các chương trình giảng dạy về tài sản và bất động sản ở bậc đại học và sau đại học ở một số nước. Thật vậy, rất ít người tốt nghiệp chuyên ngành bất động sản hoặc bất động sản có thể tiếp xúc có ý nghĩa với những chủ đề này. Vì tài sản bao gồm các cấu trúc vật chất hàm chứa sự tham gia và tương tác cá nhân, thương mại, giải trí và thể chế của xã hội, nên hầu như bất kỳ yếu tố nào liên quan đến vấn đề con người đều liên quan đến tài sản. Sau đó, thách thức là xác định kiến thức liên quan nhưng không phải là một phần của chuyên ngành tài sản và đâu là một phần thực tế của chuyên ngành này. Để trở nên hiệu quả, người tham gia vào lãnh vực tài sản cần có kiến thức về các chuyên ngành cốt lõi như khoa học vật lý, lý thuyết hành vi, khoa học chính trị, kinh tế và quản lý. Các nguyên tắc cơ bản, có thể được coi là bao gồm các công cụ, lý thuyết và khái niệm phải được hiểu biết như một điều kiện tiên quyết để tham gia tài sản hiệu quả. Tương tự, một số lĩnh vực liên quan của nền kinh tế, mà hàng hóa và dịch vụ được sản xuất và sử dụng tạo ra các tài sản thực và cung cấp các dịch vụ tài sản, là một phần của chuyên ngành bất động sản.

Để có sự nghiệp lâu dài trong lĩnh vực tài sản, cần phải có hiểu biết về môi trường của doanh nghiệp, các mối quan hệ thể chế của nó, các công cụ kỹ thuật cần thiết để hoàn thành các nhiệm vụ cơ bản, phong cách cá nhân và các thuộc tính cần thiết để quản lý hiệu quả. Kiến thức này có thể được truyền đạt và lãnh hội trong học đường, bằng cách tìm hiểu cá nhân và / hoặc thông qua kinh nghiệm. Những người mới tham gia kinh doanh bất động sản phải nhạy cảm với vấn đề sử dụng hợp lý sức mạnh của các kỹ năng phân tích vượt trội mới có được, trong đó nhận thức và kiến thức về các vấn đề môi trường quan trọng. Điều này trái ngược với những cá nhân chỉ tập trung sự hiểu biết về câu hỏi "What - cái gì" chứ không phải tỏ tường về "How - làm thế nào" của quyết định. Nhiều nhân viên tài sản lâu năm có thể xác định cách thức hành động được chỉ định nhưng nếu được yêu cầu đưa ra một lý do rõ ràng cho những quyết định của mình thì những người này sẽ khó ghi lại hoặc mô tả rõ ràng lý do cho quyết định của chính họ. Chuyên gia bất động sản thành công trong lĩnh vực bất động sản sẽ cân bằng và tích hợp các thuộc tính sau:

+ Kiến thức Môi truờng (Environmental Knowledge): kiến thức này mang lại sự hiểu biết về "ãnh thổ” cơ bản để tham gia thành công vào bất kỳ doanh nghiệp nào, đặc biệt quan trọng trong lĩnh vực bất động sản.

+ Quan điểm chiến lược (Strategic Outlook): Khi tốc độ thay đổi nhanh chóng trong cấu trúc của doanh nghiệp bất động sản đang khiến các mối quan hệ truyền thống sụp đổ và các liên 
minh quyền lực mới xuất hiện, việc định vị bản thân và tổ chức của một người về mặt chiến lược có tầm quan trọng lớn.

+ Kỹy năng kỹ thuật Quản trị Kinh doanh (BA technical skills): các phương pháp phân tích để giải quyết vấn đề, các hệ thống và thủ tục để hiểu được nền kinh tế vận hành và kiểm soát hiệu suất, và các kỹ thuật dự báo để lập kế hoạch hoạt động trong tương lai và tạo thuận lợi cho các quyết định ngân sách vốn - có vai trò quan trọng trong "bộ công cụ̂" của người quản lý tài sản.

+ Sáng kiến Khởi nghiệp (Entrepreneurial Initiative): Kinh doanh bất động sản vốn có tinh thần đổi mới khởi nghiệp ở chỗ nó điều phối các nguồn lực và ảnh hưởng đến các mô hình hành vi trong các môi trường phần lớn không có cấu trúc và nơi có thể ít tiền lệ nếu có. Những người cần trật tự, cấu trúc và khả năng dự đoán, và những người không thoải mái với sự không chắc chắn, mơ hồ, áp lực và biến động, sẽ rất tốt để nộp đơn ở nơi khác.

+ Phong cách thể chế (Institutional Style): Vai trò ngày càng chiếm ưu thế của sự kiểm soát vốn của các thể chế có nghĩa là điều kiện tiên quyết quan trọng để hoạt động hiệu quả trong lĩnh vực bất động sản là "sự tồn tại" thích hợp trong các cơ sở thể chế. Yêu cầu này vừa là một sự khác biệt với các thông lệ trước đây, vừa xa lạ với nhiều người tham gia vào các khía cạnh khác nhau của kinh doanh bất động sản.

+ Định hương quản lý (Managerial Orientation): Các điều kiện cạnh tranh hơn, các tổ chức lớn hơn và kỳ vọng cao hơn của những người tham gia phức tạp hơn đặt ra giá trị cao hơn cho định hướng quản lý đối với doanh nghiệp. Cách tiếp cận có cấu trúc nhấn mạnh vào các hệ thống lập kế hoạch và kiểm soát ngày càng trở nên quan trọng.

+ Năng khiếu Marketing (Marketing Flair): Kinh doanh bất động sản nói cho cùng liên quan đến việc mua bán trong bối cảnh của mối quan hệ cung và cầu của thị trường.

+ Kỹ năng Cá nhân và Định hướng Con người (Personal Skills and People Orientation): Yếu tố con người là hiển nhiên quan trọng trong bất kỳ doanh nghiệp nào, nó đặc biệt quan trọng đối với ngành bất động sản, do ảnh hưởng của các quyết định về tài sản đối với cuộc sống cá nhân và tổ chức của một người, cũng như vai trò của các yếu tố cảm xúc trong nhiều quyết định về tài sản. Do đó, việc tạo dựng mối quan hệ cá nhân phù hợp thường có thể là yếu tố cơ bản để đạt được kết quả tốt. Đồng thời, những đặc điểm tính cách cơ bản như sáng tạo, chính trực, bền bỉ, khả năng thuyết phục, siêng năng và chú ý đến chi tiết, tính kiên định, thuyết phục, siêng năng và chú ý đến chi tiết, đều là những yếu tố làm tăng khả năng thành công của một người trong kinh doanh bất động sản.

Manning và Roulac (2001, p. 19) đã mô tả tầm quan trọng của năng lực cảm xúc và nhận thức đối với học viên và sinh viên ngành bất động sản "Điều quan tâm nhất đối với những cá nhân chú ý đến định hướng tương lai của bất động sản và các trường đại học kinh doanh khác là kinh nghiệm mà trí tuệ cảm xúc có thể học được trong suốt cuộc đời và được dạy thành công cho sinh viên trong các chương trình kinh doanh ở đại đại học.

\subsection{Phạm vi chuyên ngành bất động sản}

Giáo dục cải thiện đáng kể năng lực của sinh viên tốt nghiệp và nâng cao cơ hội được tuyển dụng của họ. Idogho (2011) khẳng định rằng "bản chất của các cơ sở giáo dục bậc cao là phát triển con người toàn diện về tinh thần, đạo đức và thể chất và trao bằng cấp cho các sản phẩm của họ, những người được cho là xứng đáng về nhân cách và học thức. Điều này giúp họ đảm nhận vai trò lãnh đạo trong xã hội trước mắt và mở rộng của họ". Từ những điều đã đề cập ở trên, điều cấp thiết là để đáp ứng các xu hướng hiện tại và những thay đổi trong nền kinh tế, cần 
phải tiến hành đánh giá liên tục chương trình học nhằm chuẩn bị cho sinh viên tốt nghiệp vào môi trường làm việc. Giáo dục bất động sản, giống như bất kỳ khía cạnh nào khác của giảng dạy và nghiên cứu, cần được liên tục xem xét và đánh giá lại để đáp ứng nhu cầu hiện tại trong ngành.

Kiến thức cần thiết để đưa ra quyết định hiệu quả liên quan đến bất động sản trong bối cảnh toàn cầu của thế kỷ 21 vượt qua nội dung chương trình giảng dạy của giáo dục bất động sản truyền thống. Giáo dục bất động sản truyền thống, thiên về và phản ánh cách giải thích hạn hẹp, thậm chí hạn chế về các chiều và lĩnh vực của ngành học, thường phản ánh một cái nhìn hạn chế, hạn hẹp về mặt văn hóa, thậm chí là mang tính thời đại về thế giới.

Cơ bản để tham gia vào ngành bất động sản hiệu quả trong thế kỷ 21 , là sự đánh giá cao tầm quan trọng của bối cảnh toàn cầu. Sự tham gia quản lý tài sản hiệu quả vào thế kỷ mới nhất thiết phải bao trùm nhiều vùng địa lý và mức độ quan tâm, mở rộng từ mức độ thân thiết và tức thời đến toàn cầu và mở rộng nhất. Kết hợp với tầm quan trọng của toàn cầu định hướng là mệnh lệnh của sự nhạy cảm và nhấn mạnh vào những điều vốn có tính địa phương của tài sản và bất động sản. Do đó, định hướng chính là toàn cầu nhưng bỏ qua sự nhạy cảm với các quan điểm bản địa hóa hơn có thể nguy hiểm như tính cục bộ chưa nhận diện tác động của các áp lực toàn cầu. Định hướng của phần lớn những người tham gia vào bất động sản và bất động sản chủ yếu là mang tính địa phương hơn là toàn cầu.

Tính hai mặt cục bộ-toàn cầu được dung hòa bằng cách xem xét rằng tài sản bao gồm nhiều phân khúc hoặc mức độ tham gia, định hướng và kinh nghiệm riêng biệt. Sự tham gia hiệu quả vào tài sản bắt nguồn từ việc xem xét các mối quan tâm từ vĩ mô nhất đến vi mô nhất cũng như nhiều mối quan tâm trung gian. Để giải quyết vấn đề này, chuyên ngành bất động sản gồm các quy trình, thể chế, người tham gia, chức năng, thị trường, lý thuyết và khái niệm, mô hình, quy tắc và quy định - làm trung gian và tạo ra các kết nối giữa các giá trị của xã hội và các mô hình không gian.

Ngoài những điều được kể trên còn rất nhiều các bên liên quan trong các quyết định về bất động sản, ngoài người ra quyết định chính, người khởi xướng và kiểm soát quyết định ảnh hưởng đến chuyên ngành này. Mặc dù sự nhạy cảm đối với các hệ quả hệ thống của tài sản có tầm quan trọng lớn đối với sự thành công của một giao dịch cụ thể và cả đối với xã hội, nhưng cách các bên liên quan nên đưa những mối quan tâm này vào các quyết định về tài sản của họ lại quá hiếm khi được xem xét một cách rõ ràng.

\section{Kết luận}

Cuộc tranh luận đang diễn ra về những chuyên môn và kỹ năng liên quan đến tài sản (hoặc bất động sản) có được xem như một ngành học vẫn còn được diễn ra. Nhiều học giả xem bất động sản là lĩnh vực nghiên cứu chức năng hay một lĩnh vực đào tạo thương mại. Nhiều tác giả đề cập đến bất động sản như một lĩnh vực nghiên cứu đa ngành nhưng không thống nhất được mô hình chính xác cho một ngành học. Tuy nhiên, Boyd (2005) đã khẳng định rằng nhu cầu xem bất động sản là chuyên ngành cung cấp kiến thức và kỹ năng chuyên sâu là điều cần thiết và nó cần xem xét nhiều lợi ích của các bên liên quan khác nhau.

Chuyên gia bất động sản sở hữu kiến thức cần thiết để tham gia hiệu quả vào bất động sản trong bối cảnh toàn cầu có kiến thức để theo dõi, phân tích, tổng hợp, ra quyết định, và truyền đạt mọi tương tác của họ với quá trình bất động sản. Tất cả những hoạt động trên sẽ xây dựng nên tính bền vững, đóng góp cho xã hội nhiều hơn và quan trọng là thu được cái nhìn tích cực từ phía công chúng. Do vậy, nền tản không thể chối bỏ của những hoạt động là sự tôn trọng đất đai, di sản văn hóa của người bản địa, nhấn mạnh vào thiết kế đặc biệt, chú ý đến nhu cầu của người sử dụng, sự xuất sắc trong thực hành chuyên môn, trải ngiệm dịch vụ tuyệt vời, và đáng 
tin cậy.

Trong bối cảnh Việt Nam có thể tham khảo cách tiếp cận của một số nước Châu Âu để bổ sung thêm khối kiến thức trong lĩnh vực bất động sản được trình bày như ở trên, phản ánh sự phát triển của quá khứ, hiện tại và các định hướng tương lai khi mà nhu cầu của thị trường đã và đang thay đổi khá nhanh. Khuôn khổ này nhằm đáp ứng và phản ánh những ảnh hưởng chi phối đáng kể như cách công nghệ định hình lại các mô hình sử dụng không gian, ảnh hưởng và ràng buộc của pháp luật, vai trò của các tổ chức bất động sản chuyên nghiệp, chứng khoán hóa tài sản không ổn định và vị thế không chắc chắn của chuyên ngành bất động sản trong giới học thuật. Hơn nữa, khung khái niệm nhằm phản ánh các quyết định quan trọng về tài sản, bao gồm các quyết định liên quan đến việc sử dụng không gian của các hộ gia đình và doanh nghiệp, tham gia tài chính, giám sát quản lý công và vai trò của các cá nhân với tư cách là công dân có trách nhiệm. Ngoài ra, xem xét thêm một số nhu cầu cụ thể của từng bên liên quan quan trọng như công ty bất động sản, người học, xây dựng chính sách, và vân vân.

Trong khi đó, đào tạo chuyên ngành bất động sản có thể tiếp cận dưới gốc độ đa dạng như chứng chỉ, giấy phép hành nghề. Bài tham luận này chỉ dừng lại ở phạm vi chỉ ra nhu cầu bổ sung thêm một số môn học vào chương trình đào tạo một cách bài bản hơn để đóng góp vào xây dựng thị trường bất động sản bền vững hơn, minh bạch hơn và mang lại lợi ích cho nhiều người hơn.

Ngành bất động sản đã chuyển từ định hướng giao dịch sang định hướng chiến lược. Kết quả và phần thưởng đáng giá sẽ định hướng cho những các cá nhân tham gia vào ngành là kết quả của kiến thức vượt trội về quy trình tài sản và khả năng hành động dựa trên kiến thức đó. Chiến lược không còn có thể là điều cần biết sau một giao dịch, mà chiến lược phải là hướng dẫn trọng yếu để ra quyết định kinh doanh. Tham gia vào bất động sản hiệu quả bắt nguồn từ việc hiểu được bản đồ chiến lược của ngành bất động sản, xác định các lĩnh vực kiến thức chính và mối liên hệ giữa các lĩnh vực kiến thức.

\section{Tài liệu tham khảo}

An Huy (2019). Bloomberg: Thị truờng bất động sản cao cấp Việt Nam đang "nóng" [Bloomberg: Vietnam luxury real estate market is "hot"]. Retrieved October 20, 2019, from https://vneconomy.vn/bloomberg-thi-truong-bat-dong-san-cao-cap-viet-nam-dang-nong20190219093603279.htm

Boyd, T. (2005, January). Stakeholder impact on property education programs. In Proceedings of the 11th Pacific Rim Real Estate Conference (PPRES) (pp. 1-15).

Dewulf, G., Krumm, P., \& Jonge, H. D. (2000). Successful corporate real estate strategies. London, UK: Arco Publishers.

Hamzah, H., Yahya, Z., Sarip, A. G., \& Adnan, Y. M. (2016). Impact of Entrepreneurship Education Programme (EEP) on entrepreneurial intention of real estate graduates. Pacific Rim Property Research Journal, 22(1), 17-29.

Idogho, P. O. (2011). Higher education in Nigeria and the challenges ahead. European Journal of Educational Studies, 3(2), 269-276.

MacGregor, N. (2020). Toàn cảnh bất động sản Việt Nam 25 năm qua 1995-2020 [Overview of real estate in Vietnam 25 years from 1995-2020]. Retrieved October 25, 2019, from https://vn.savills.com.vn/blog/article/185279/vietnam-viet/vietnamese-property-overview1995-2020.aspx 
Palm, P., \& Pauli, K. S. (2018). Bridging the gap in real estate education: higher-order learning and industry incorporation. Journal of Real Estate Practice and Education, 21(1), 59-75.

Roulac, S. E. (1996). State of the discipline: Malaise or renaissance? Journal of Real Estate Research, 12, 111-122.

Roulac, S. E. (1998). Property and ptolemy, copernicus and commerce: Toward a strategic perspective for global property involvements. Journal of property valuation and investment, 16(5), 431-446.

Schulte, K., Schulte-Daxbo“k, G., Holzmann, C., \& Wiffler, M. (2005). Internationalisation of Real Estate Education. Paper presented at the ERES Conference Dublin, Ireland.

Stephen, R. (2001). Corporate property strategy is integral to corporate business strategy. Journal of Real Estate Research, 22(1/2), 129-152.

Washer, P. (2007). Revising key skills: A practical framework for higher education. Quality in Higher Education, 13(1), 57-67.

Webb, J. R., \& Albert, J. D. (1995). Evaluating the real estate journals: The mainstream finance perspective. Journal of Real Estate Research, 10(2), 217-226. 